\title{
The Compliance Challenges in Emissions Control Regulations to Reduce Air Pollution from Shipping
}

\author{
Khanh Q. Bui and Lokukaluge P. Perera \\ Deparment of Technology and Safety \\ UiT The Arctic University of Norway \\ Troms $\emptyset$, Norway \\ \{khanh.q.bui, prasad.perera $\} @$ uit.no
}

\begin{abstract}
One of the thorny problems perplexing the maritime industry is to comply with existing and soon-to-be-enacted regulations towards emissions reduction from shipping. This problem has been discussed in this study under three viewpoints: i) the marine engine efficiency, ii) the decision-making process for selecting the technologies for reducing air emissions from shipping and iii) the challenges in the shipping industry during the era of digitalization. In the section of the marine engine efficiency, the fundamental laws of thermodynamics in relation to a Carnot cycle/heat engine have been illustrated to show the maximum efficiency that an engine can achieve within its operational temperature range. In the section of the decision-making process, the selection of technologies for reducing emissions from shipping, a variety of possible options has been discussed: e.g. using compliant fuels with low sulphur content in the current machinery; integrating an emission abatement technology such as marine scrubber as an after-treatment device; opting for alternative fuels such as Liquefied Natural Gas (LNG) or Methanol and future ship propulsion with an array of alternatives. Nevertheless, it can be a challenge for decision-makers (shipowners and operators) to select the most suitable alternatives for regulatory compliance in reducing emissions from shipping. It involves with multiple criteria decision making (MCDM) in which a number of alternative options are assessed with regard to multiple factors and sub-factors as described in this study. In the section of the challenges for the shipping industry in the era of digitalization, Advanced Data Analytics for ship performance monitoring is considered to overcome the handling challenges in large-scale ship performance and navigation data sets.
\end{abstract}

Keywords-Emissions control, alternative options, energy efficiency, data analytics.

\section{INTRODUCTION}

Shipping industry has been considered as the life blood of global economy, transporting around $90 \%$ of international trade [1]. Although the shipping industry is the most fuel-efficient mode of cargo transportation, it has been criticized for the contributor of roughly $3 \%$ of total global carbon dioxide $\left(\mathrm{CO}_{2}\right)$ emissions [2]. Furthermore, it is also responsible for producing global sulphur oxides $\left(\mathrm{SO}_{\mathrm{x}}\right)$ and nitrogen oxides $\left(\mathrm{NO}_{\mathrm{x}}\right)$ emissions at the figure of $5-10 \%$ and $15-30 \%$, correspondingly [3]. Air emissions from ships are addressed in the Annex VI of the International Convention for the Prevention of Pollution from Ships (MARPOL). As regards the concerted effort for reducing greenhouse gas $(\mathrm{GHG})$ emissions which $\mathrm{CO}_{2}$ is the main pollution contributor, the International Maritime
Organization (IMO) has introduced two mandatory mechanisms from both technical and operational aspects namely Energy Efficiency Design Index (EEDI) and Ship Energy Efficiency Management Plan (SEEMP), which took effect from 1 January 2013. The former is the technical standard which applies for new-built vessels while the latter is an energy efficient improvement plan required onboard existing vessels during its life-cycle operation [4]. In order to confirm their commitment on decreasing the GHG emissions from international shipping, the IMO has also adopted a resolution to at least halve GHG emissions by 2050 in comparison with 2008 while striving for phasing them out entirely [5].

As regards the effort for the emissions reduction of air pollutants such as $\mathrm{SO}_{\mathrm{x}}, \mathrm{NO}_{\mathrm{x}}$ and indirectly particulate matter (PM), the Emissions Control Areas (ECAs) have been introduced. The vessels operating within ECAs are required to use fuel oil with the level of sulphur content of $0.1 \%$. It should be noted here that the upcoming global sulphur cap that requires sulphur content limit of $0.5 \%$ will go into effect from 1 January 2020 [6]. With the view of ensuring a consistent enforcement and implementation of this limit, the carriage ban on noncompliant fuel has been adopted by the IMO, entering into force from March 2020 [7]. In addition, Tier III $\mathrm{NO}_{\mathrm{x}}$ emission limits apply for marine diesel engines installed on new-built vessels constructed on or after 1 January 2016 ECAs except for the Baltic Sea and the North Sea. Nevertheless, the IMO approved these areas as $\mathrm{NO}_{\mathrm{x}}$-ECA, taking effect from 1 January 2021 [8]. Given that the afore-mentioned emissions control regulations, this paper will discuss three perspectives: i) the marine engine efficiency, ii) the decision-making process for selecting the technologies for reducing air emissions from shipping and iii) the challenges in the shipping industry during the era of digitalization. Those are discussed in the following sections.

\section{MARINE ENGINE EFFICIENCY}

Marine engines can be considered as the center of ship energy efficiency, where adequate measures to reduce their emissions due to operational conditions should be considered. There are various theories that have been considered towards improving energy efficiency in marine engines. Firstly, the most important and fundamental theory, i.e. the second law of thermodynamics is further illustrated in this section. This law presents a possible upper limit of the engine efficiency, therefore that can also be a measure of energy efficiency in the respective 
ships. The second law of thermodynamics in relation to the Kelvin-Plank Statement can be formulated as:

It is impossible for any device that operate on a cycle to receive heat from a single reservoir and produce a net amount of work.' [9].

One should note that marine engines are operating in a Diesel and/or Otto cycles. Therefore, these engines are governed by the Kelvin-Plank Statement, where that should have more than a single reservoir to produce the respective mechanical energy. The concept of a heat source and sink to supply and absorb energy during an engine cycle can be introduced for the same reason. That is further illustrated in Figure 1, where the heat, $\mathrm{Q}_{\mathrm{H}}$, is transferred from the high-temperature heat source to the low-temperature heat sink as the heat, $\mathrm{Q}_{\mathrm{L}}$, through the heat engine.

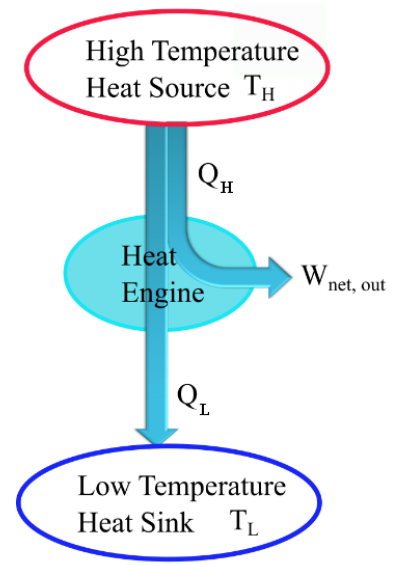

Fig. 1. A general representation of a heat engine.

The Kelvin-Plank statement illustrates that a heat engine should operate between a heat source and sink. Therefore, a considerable amount of heat should be absorbed by the heat engine to produce work, $\mathrm{W}_{\text {net, out }},\left(=Q_{H}-Q_{L}\right)$, and a portion of the same heat should be released into the heat sink as waste heat. Since a portion of the absorbed heat should release to produce the respective work by the heat engine, no heat engine can have the thermal efficiency of $100 \%$. Therefore, the next step is to quantify the respective amount of heat should be released and absorbed into the heat source and sink, respectively. The same outcome can be used to calculate the maximum efficiency of the respective heat engine.

To quantify the efficiency of a marine engine, the concept of a heat engine should be further investigated. The thermal efficiency, $\eta_{t h}$, of a heat engine (reversible or irreversible) can be categorized as:

$$
\eta_{t h}=1-\frac{Q_{L}}{Q_{H}}
$$

It has been shown that ratio between the heat absorbed and released by a heat engine relates to the temperature ratio between the heat sink and source for a reversible heat engine [9]. An idealized heat engine that operates on a reversible Carnot cycle can be categorized as a Carnot heat engine. Therefore, the efficiency of a Carnot heat engine, or any reversible heat engine can be categorized as:

$$
\eta_{t h, r e v}=1-\frac{T_{L}}{T_{H}}
$$

One should note that (2) is an ideal case, therefore that can be the maximum efficiency a marine engine can achieve in a theoretical level. That shows: if the operational temperature $\left(\mathrm{T}_{\mathrm{H}}\right)$, i.e. combustion temperature, can be increased then the efficiency of the marine engine can be improved. The complete burning of bunker fuel due to high combustion temperature can increase the engine efficiency. However, marine engines can produce a considerable amount $\mathrm{NO}_{\mathrm{x}}$ under high temperature conditions. Therefore, not only can the high operational temperature increase the engine efficiency but it also increases $\mathrm{NO}_{\mathrm{x}}$ emissions. On the other hand, if the environmental temperature $\left(T_{L}\right)$, can be decreased, then the efficiency of the marine engine can also be improved. It is well known that when marine engines operate in cold environments, its efficiency is higher. However, unburned fuel in marine engines can be resulted under low combustion temperature conditions. As a conclusion, the energy efficiency that a marine engine can achieve is limited to these upper and lower temperature bounds, i.e. Carnot engine efficiency under its operational temperature range. Even under any modern technological advancements, this engine efficiency level cannot be exceeded. Therefore, these efficiency levels in marine engines can play an important role while selecting the technology alternatives to reduce ship emissions under the regulatory pressure from the maritime authorities.

\section{Technology Decision-MAKING Process}

There are various operational alternatives to meet the requirements for emissions reduction from marine engines. One of the options is to use compliant fuels with lower sulphur content. The second option is to operate on heavy fuel oil (HFO) along with the installation of exhaust gas cleaning systems (e.g. maritime scrubbers). Alternative fuels such as Liquefied Natural Gas (LNG) or Methanol can also be considered as other options. Future marine engines would be the utilization of Liquefied petroleum gas (LPG), Compressed Natural Gas (CNG), biofuel (e.g. Liquefied Bio Gas - LBG), hydrogen, solar power, wind power or fuel cells.

When it comes to evaluating these alternative options for regulatory compliance to reduce emissions from ships, there are numerous factors should be taken into consideration. Generally, these factors have been explained from economic and environmental point of view. However, each alternative solution will also exert a social impact [10]. The integration of social factor into the evaluation process has been addressed by several scientific studies [11, 12]. These factors (economic, environmental and social) are regarded as three pillars of sustainability [13]. Furthermore, technical and political factors have been also incorporated into the sustainability evaluation for selecting alternative compliance solutions [14]. Other factors such as safety, logistics, security and ethics factors can be considered in the decision-making process for future marine fuels [15].

Under these dimensional factors, ship owners and operators (decision-makers) also consider a wide range of sub-factors. Capital cost, operational cost, life-cycle cost and fuel price are 


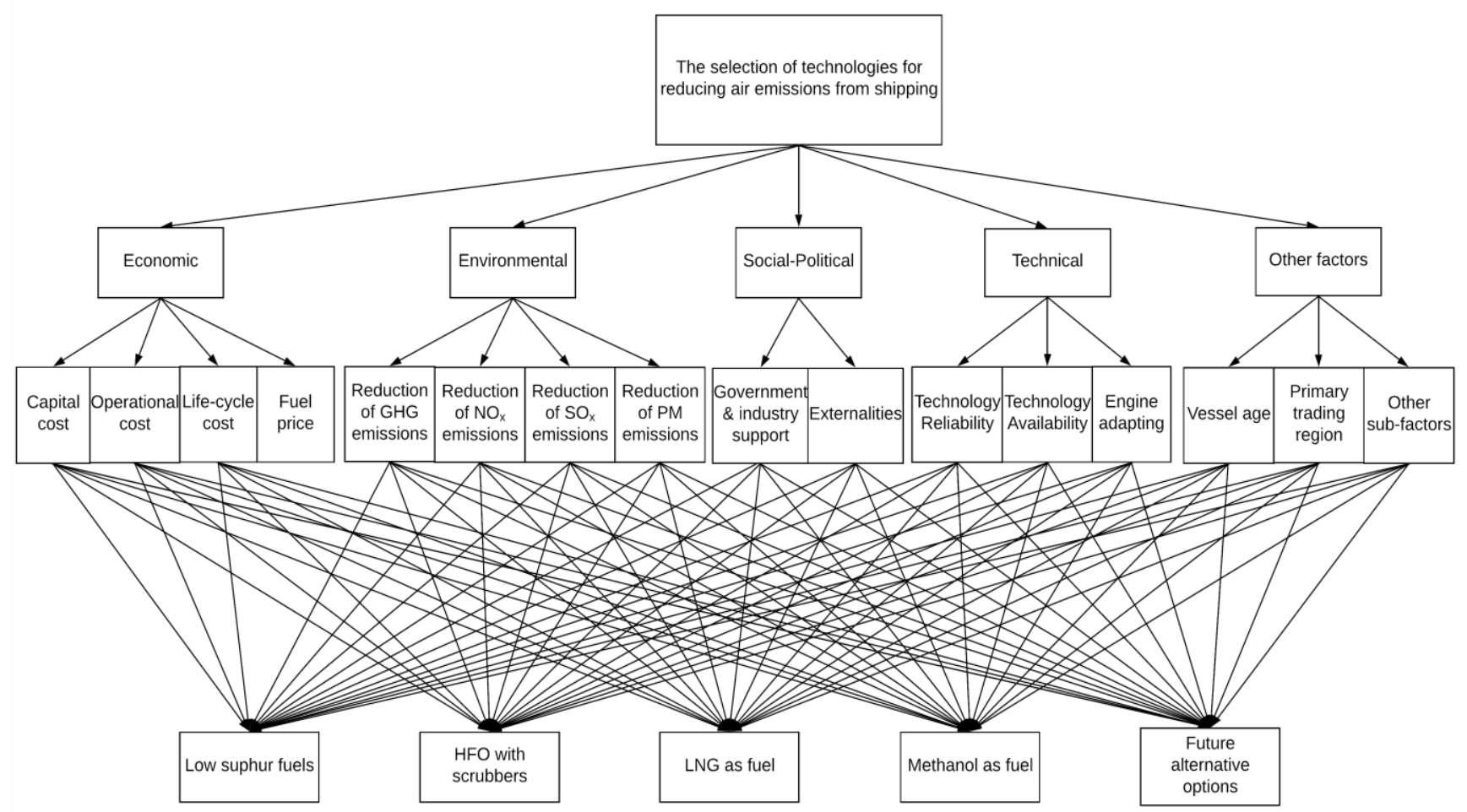

Fig. 2. Decision-making hierarchy of the selection of technologies for reducing emission from shipping

sub-factors that can be listed under the economic factor. There are several sub-factors that can be listed under the environmental factor, including the reduction of air emissions $\left(\mathrm{GHG}, \mathrm{SO}_{\mathrm{x}}\right.$, $\mathrm{NO}_{\mathrm{x}}$, and PM emissions). In terms of social-political factor, the sub-factors can be governmental \& industry support and externalities. In terms of technical factor, the sub-factors can be technology availability, technology reliability, and engine adapting. Apart from that, some sub-factors that are hard to be categorized such as the vessel age and primary trading regions need to be carefully considered by decision-makers. Therefore, conducting this evaluation based on aforementioned dimension is multiple criteria decision making (MCDM) analysis that involves multi criteria or factors evaluation from the views of experts for selecting rational alternative solutions as demonstrated in Figure 2. The ultimate goal of this approach is to select the best alternative option among others. In other words, after factor and sub-factor evaluations, the alternative options are prioritized from the best to the worst.

Another concern should be emphasized is that the MCDM analysis is conducted under trade-off environment, where factors or sub-factor are normally of conflicting nature [16]. Indeed, the respective sub-factors within the technical domain should have substantial impacts on the economic and environmental factors. Likewise, the sub-factors within the social-political domain should have considerable influences on the economic, environmental, and technical domains. For example, regulations given by maritime authorities may have great impacts on economic development, environmental protection and technology advances [14]. Further challenges on this analysis are the inconsistent and vague information problems. The inconsistent problem refers to the fact that it is not easy to arrive at conclusions from the literature regarding the values of alternative options with respect to sub-factors. For example, some studies concluded the reduction of $75-90 \%$ PM emissions when using scrubbers meanwhile other studies indicated that there is no reduction. Taking the economic subfactors as an example for the vague problem, the capitol cost, operational cost and fuel price are not fixed due to the unpredictable oil market. Besides, the values of environmental sub-factors (e.g., the reduction of $\mathrm{GHG}, \mathrm{NO}_{\mathrm{x}}$ and $\mathrm{SO}_{\mathrm{x}}$ ) with respect to alternative options are represented as intervals rather than crisp values. Furthermore, there are several sub-factors that are unquantifiable (e.g., government \& industry support, primary trading region).

There are several approaches to address the MCDM problem are considered. In the classical MCDM methods, the important weights of factors and the ratings of alternatives are normally represented as crisp values. Nonetheless, it is inadequate to use crisp values to stimulate the decision-making problem under fuzzy environment due to vague and imprecise information. Since the MCDM analysis involves the views of experts and decision-makers, some methods have experienced the difficulty in handling the uncertainties and ambiguity of human judgments on the priority weights of factors and the ratings of alternatives. Fuzzy set theory or fuzzy logic, firstly was proposed by [17] is an effective tool to surmount the respective problems. The fuzzy set theory was incorporated in above decision-making process to expresses the human preferences towards factors and alternatives evaluation by means of linguistics variables and fuzzy numbers. In literature, several studies have applied fuzzy set theory into their techniques in order to overcome the MCDM problem especially for the assessment of air pollution prevention 
measures under compliance with emissions control regulations. A generic model, which incorporates the fuzzy Analytic Hierarchy Process (AHP) and VIKOR (VIseKriterijumska Optimizacija I Kompromisno Resenje) techniques for selecting the emissions reduction alternative technologies for ships, was presented in [12]. [18] presented an integrated method combining fuzzy logarithmic least squares and fuzzy Technique for Order Preference by Similarity to Ideal Solution (TOPSIS) for measuring the sustainability of alternative marine fuels. The MCDM method that combines Dempster-Shafer theory and the trapezoidal fuzzy AHP for the selection of sustainable alternative energy source for shipping was carried out [14]. The integration of Fuzzy Quality Function Deployment (FQFD) and fuzzy TOPSIS method for prioritizing mechanism of lowcarbon shipping measures was undertaken in the research work [19]. The fuzzy AHP method was applied to prioritize the weight of ship energy efficiency measures in accordance with SEEMP [20]. The improved Gaussian fuzzy AHP method was conducted by [21] for investigating the selection of shipping technology by dynamic capabilities theory.

Each of above approach has its strengths and weaknesses. In addition, those studies have only applied either the fuzzy AHP or TOPSIS technique. The fuzzy integrated MCDM approach proposed by [11] has integrated the fuzzy AHP in combination with the fuzzy TOPSIS for selecting technological alternatives for regulatory compliance towards emission reduction from shipping. Several advantages of this integrated fuzzy MCDM include as follows: (i) the fuzzy AHP technique with the utilization of the fuzzy comparison ratio can be able to deal with the ambiguity in the model by precisely resembling the human thinking; (ii) in the fuzzy TOPSIS technique, the computation process might be programmed easily; human choices are embodied in the logical way; the number of stages remains the same irrespective of the number of factors and it reveals a scalar value that represents simultaneously the most and the least alternatives. Taking three domains of sustainability (economic, environmental and social) into account simultaneously, this study analyzed nine sub-factors with four feasible alternatives for the purpose of ranking these alternatives from the most preferable to the worst preferable. In order to exemplified the proposed fuzzy MCDM approach, a real case study was conducted with the interactions from vessel owners as decision makers. Firstly, after identifying and evaluating factors, subfactors and feasible alternatives, they were required to assign the important weights of different factors and sub-factors by pairwise comparison. In this phase, the fuzzy AHP was deployed to obtain the factors and sub-factors weightings as the inputs for the next phase. Secondly, they were requested to rate each performance of alternatives with regard to each sub-factor. In this phase, alternatives were prioritized with the help of the fuzzy TOPSIS. Due to the fact that this research has fuzziness in its nature, during the evaluation process given by vessel owners, the linguistics variables were deployed and then converted into fuzzy numbers.

According to the outcomes of the above study, Low-sulphur fuels have been recognized as the most suitable alternative for regulatory compliance followed by Methanol. The third and fourth in the ranking results were Scrubbers and LNG respectively. Economic factor, among other factors, attached the most interest from decision-makers when it comes to investment in emissions reduction measures. Sensitivity analysis has been undertaken to reveal that that capital cost was of paramount importance in the decision-making process. Not only does the outcome reflects the current situation of the maritime industry in which inertia and financial issues are taken into consideration, but it is also in-line with some studies in the literature [12, 22]. In order to abide by the environmental regulations, Low sulphur fuels are likely to be a mainstream resolution in the short-term. It is envisaged that the legislation on emissions from shipping will be stricter in the future. Therefore, in the medium and long run, vessel owners and operators should consider regulatory changes and their actual conditions to make rational decisions. In this regard, they can add or remove the factor and sub-factor based on their preferable interests in the proposed decisionmaking process. This proposed method can be extended to the future scenario which has numerous factors, sub-factors and potential alternatives. It might be potentially applicable to other research areas that involve decision-making process under vague conditions.

\section{INDUSTRIAL DIGITALIZATION}

\section{A. Challenges of big data in the shipping industry}

The shipping industry is standing on the brink of the fourth industrial revolution (as known as Shipping 4.0 or Cybershipping) which provides numerous possibilities for online control and off-line analytics [23]. The rapid development of Internet of things (IoT) with the utilization of sensor technologies as well as data acquisition systems can facilitate maritime operations by means of real-time monitoring and control systems onboard. Nevertheless, the problem arising from this development is the explosive growth of data. The data generated from above systems onboard is very large in volume, complex to process and analyze by conventional data processing methods. The large-scale data is regarded as "Big Data" [24] when the shipping sector is moving into the imminent era of digitalization. Therefore, it is essential that new methods and tools should be developed for handling the big data. Those tools and techniques are parts of big data analytics for the purpose of grasping the meaning of data. Another challenge that the shipping industry will encounter in the future of industrial digitalization is environmental legislation compliance. Taking the ambitions to minimize the GHG emissions from shipping, there are two data-oriented regulations called Data Collection System (DCS) and Monitoring, Reporting and Verification (MRV) introduced by the IMO and the European Union (EU) respectively. Both regimes are mandatory and aim to collect and analyze emissions data from ships. The first regime that will enter into force on 1 January 2019 covers emissions from shipping globally [25] while the second that entered into force on 1 January 2018 focuses $\mathrm{CO}_{2}$ emissions from shipping activities to, from and within EU waters [26].

It should be noted here that the quality of full-scale data sets may play prominent role under these afore-mentioned regulations. In this sense, it relates to the data veracity which is one of the four major features of big data, referred to as the four V's: data volume, data velocity, data variety, and data veracity [27]. Data veracity refers to the data accuracy and trustworthiness or uncertainty of data. It is a common issue in 
the automation and sensor systems that data can sometimes be of dubious or erroneous format. This is due to the fact that the sensor has failed or there is an abnormal event within the systems $[23,28]$. The data will not be carried out the quality checks which leads to the uncertainty of how much the output data is incorrect. It may disturb the analytical processes and result in erroneous interpretation. The U.S. economy has to pay about $\$ 3.1$ trillion a year because of poor data quality [27]. Data scientists spend much of their time for cleaning up the data, accounting for $75-80 \%$ [29]. Therefore, data veracity should be properly addressed when performing big data analytics. Big data analytics is believed increasingly important and exerting profound impacts on maritime operations such as environmental compliance and vessel performance monitoring.

\section{B. Data analytics for energy efficient ship operations and performance management}

In the literature, a number of data analysis studies with different methods has been conducted with the aim of achieving energy efficient ship operations and performance management. A theoretical model was proposed by [30] for the simulation of ocean vessels for operational optimization. On the other hand, statistical models were undertaken by several studies. [31] presented data analysis on ship energy efficiency of inland river ships then compared them with that of ocean-going ships. In the research work of [32] preliminary analysis was undertaken for establishing trends and exploring data products in order to improve vessel performance towards fuel efficiency. [33] presented data analysis for evaluating ship behavior in a case of a bulk carrier. Data analysis for determining the fuel efficient performance of a ship was presented by [34]. Due to the recent development of sensor technologies and data acquisition systems, several statistical models have been presented: artificial neural network [35, 36], multiple linear regression [37] and kernel methods [38]. Recently, there are some researches proposing various applications of big data analysis in the maritime domain. [39] developed a decision support system for vessel speed optimization using weather archive big data. [40] proposed a big data analysis for optimizing vessel energy efficiency. The marine engine centered data analytics was undertaken to improve energy efficiency in [41] and understand marine engine operating regions with respect to vessel navigation in [42]. Another approach with statistical analysis and visualization technique was proposed by [43] to observe vessel speed power performance under apparent wind profile.

\section{Advanced Data Analytics}

It can be observed from the recent literature that various conventional mathematical models have been used for data analysis. However, these models have not addressed properly the big data challenges such as erroneous data conditions, system-model uncertainty, estimation algorithm failures, data visualization challenges and high computational power. It may lead to the deterioration of the quality of information derived from the respective data sets. In order to overcome such problems, a big data analytics approach, so called Advanced Data Analytics that includes tools and techniques based on Machine Learning (ML), Artificial Intelligence (AI) and statistical data analysis is proposed to deal with the large-scale data sets for ship performance monitoring towards energy- efficient and environmental-friendly maritime operations in the future.

The overview of the proposed Advanced Data Analytics is represented in Figure 3. Advanced Data Analytics should include the domain knowledge (e.g., the vessel operation \& navigation conditions, ship dynamics \& hydrodynamics, automation \& navigation systems). A number of marine engine modes of data flow path for ship performance monitoring has been entailed with several appropriate analytics such as the development of data driven digital models, descriptive analytics, diagnostic analytics, visual analytics, predictive analytics and decision analytics. First of all, the data sets that are attained from onboard sensors and data acquisition systems can be grouped in a high dimensional space as the clusters of vessel performance data. These data clusters indicate navigational and operational information of vessel in respective scenarios (e.g., enginepropeller operating modes and trim-draft combination). The structure of each data cluster can be identified by data digital models [28]. Hence, the development of these data digital models plays pivotal role in the data handling process. In this regard, the statistical techniques (e.g., histograms and principal component analysis) are conducted in order to observe the data clustering relationship among parameters such as engine power, shaft speed and fuel consumption. These parameters will be visualized in order to capture the proper and abnormal regions that represent the vessel performance conditions and data anomalies correspondingly. The digital models then interact respectively with descriptive and diagnostic analytics.

As regards descriptive analytics, the data sets are transferred through two anomaly data filters to identify missing data points as preliminary data anomalies (filter 1) and sensor faults and system abnormal events as secondary anomalies (filter 2 ). The first anomaly data filter may detect the max-min values while the second anomaly data filter may detect the outliers of digital models. However, the interpretation of these data will not be well-executed without the domain knowledge as previously mentioned. The digital models may be further improved by such expertise. A significant amount of data anomalies can be removed and recovered in the diagnostic analytics. Therefore, the instantaneous data sets of vessel performance can be at a higher level of accuracy and trustworthy. Afterwards, the improved data sets of ship navigation and operation are visualized properly within visual analytics. In the process of predictive analytics, vessel navigation and ship system operation behavior can be predicted. It should be noted that the visual analytics and predictive analytics are also supported by the same data driven digital models. Ultimately, the processed data are utilized under decision analytics and appropriate Key Performance Indicators (KPIs) with respect to propulsion power and engine emissions are expected to be set. As a result, the decision-making process can be strengthened.

By way of analyzing the data sets with proper techniques, the proposed Advanced Data Analytics can reflect and learn from the past data. For example, it will gain the capability to self-learn (i.e. the data structure can learn itself), self-clean (i.e. data anomalies can be detected, filtered out and recovered). Moreover, it will assist vessel operators in monitoring in realtime of vessel operational performance. For instance, the respective data structures can provide vessel operators with 


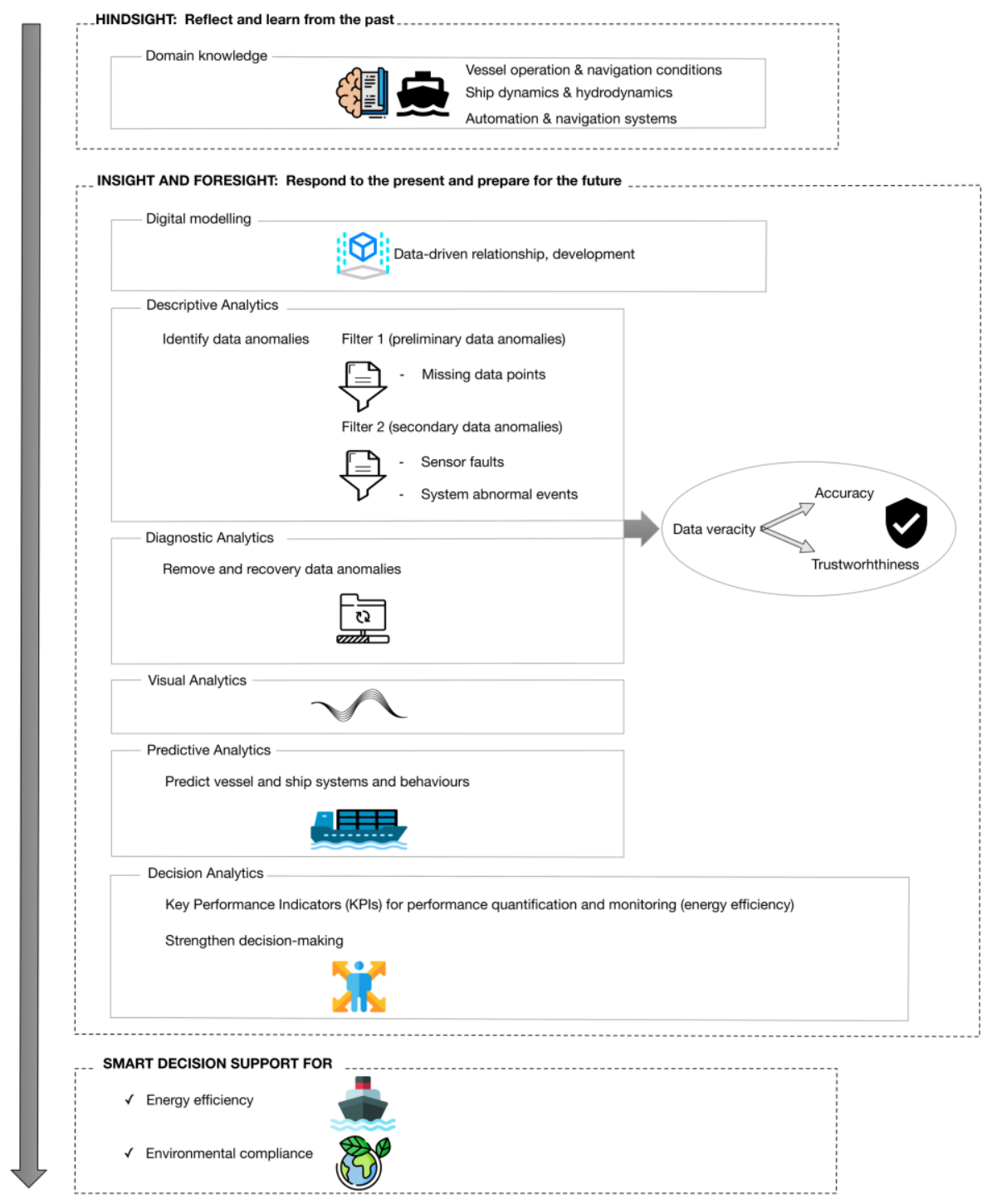

Fig. 3. Representation of Advanced Data Analytics

useful visualization in terms of vessel and ship systems performance. Future work may include emerging analytics methods that are promising to help vessel operators with predicting its performance based on current observations (e.g. what-if scenarios). The proposed approach would be a smart big data analytics that has the ability to overcome the respective challenges of the future shipping industry under industrial digitalization. Furthermore, it would be also a decision support for vessel operators to comply with environmental legislation and achieve optimized and energy efficient vessel operations.

\section{CONCLUSION}

The shipping industry is now dealing with the regulatory turbulence towards achieving the respective objectives in energy efficiency and emissions control. In this paper, the challenges of the respective regulatory compliance have been discussed from theoretical and operational point of views. In the theoretical point of view, the concept of the marine engine efficiency has been illustrated, based on the second law of thermodynamics in connection with a Carnot cycle. In this matter, the maximum efficiency that a marine engine can achieve is limited to the Carnot engine efficiency, i.e. within its operational temperature range. Hence, the concept should be taken into consideration while selecting technological alternatives for emissions reduction from ships.

In the operational point of view, the selection of alternative options for reducing emissions from shipping has been evaluated under multiple factors and sub-factors. It would be a challenge for vessel owners or operators to select the most viable alternatives because it involves a wide variety of factors within several dimensional domains and the technologies can vary, rapidly. Furthermore, the trade-off nature that attaches to this analysis may make it more complicated. Another barriers when 
conducting this analysis are the inconsistency and vagueness of information. The fuzzy-based approach which integrated the fuzzy AHP and the fuzzy TOPSIS was proposed by [11] to overcome these problems. The outcomes of this study have noted that Low sulphur fuels would be the most suitable option in near future of regulatory compliance for emissions reduction. Since the capitol cost has the most impact on the proposed method, it is the most important concern for decision-makers when selecting technologies to reduce air pollution from shipping. Finally, the Advanced Data Analytics for ship performance monitoring was discussed to handle the big data challenges in ship operational manners. The proposed Advanced Data Analytics [44] along with the limitations in marine engine efficiency concepts and decision-making process can be a stateof-the-art approach to achieve an optimized vessel performance towards energy-efficient and environmental-friendly maritime operations in the future.

\section{REFERENCES}

[1] UNCTAD, "Review of Maritime Transport 2018," in "Review of Maritime Transport," the United Nations Conference on Trade and Development, The United States of America, 2018.

[2] T. Smith et al., "Third IMO GHG Study 2014: Executive Summary and Final Report," International Maritime Organization, First presented to Marine Environment Protection Committee 67 as MEPC 67/INF.3, 2014, [Online]. Available: http://www.imo.org/en/OurWork/Environment/PollutionPreventio n/AirPollution/Pages/Greenhouse-Gas-Studies-2014.aspx.

[3] V. Eyring et al., "Transport impacts on atmosphere and climate: Shipping," Atmospheric Environment, vol. 44, no. 37, pp. 47354771, 2010/12/01/ 2010.

[4] Z. Bazari. IMO Train the Trainer (TTT) Course on Energy Efficient Ship Operation Module 2 - Ship Energy Efficiency Regulations and Related Guidelines [Online] Available: http://www.imo.org/en/OurWork/Environment/PollutionPreventio n/AirPollution/Documents/Air\%20pollution/M2\%20EE\%20regula tions\%20and\%20guidelines\%20final.pdf

[5] IMO, "UN body adopts climate change strategy for shipping," ed: International Maritime Organization (IMO), 2018.

[6] IMO, "IMO sets 2020 date for ships to comply with low sulphur fuel oil requirement," ed: International Maritime Organization (IMO), 2016.

[7] IMO, "Implementation of sulphur 2020 limit - carriage ban adopted," ed: International Maritime Organization (IMO), 2018.

[8] IMO, "Marine Environment Protection Committee (MEPC), 70th session, 24-28 October 2016," ed: International Maritime Organization (IMO), 2016.

[9] Y. A. Çengel and M. A. Boles, Thermodynamics: an engineering approach. McGraw-Hill Education 2015.

[10] F. Ballini, A. I. Ölçer, J. Brandt, and D. Neumann, "Health costs and economic impact of wind assisted ship propulsion," Ocean Engineering, vol. 146, pp. 477-485, 2017/12/01/ 2017.

[11] K. Q. Bui, "Selecting technological alternatives for regulatory compliance towards emissions reduction from shipping: An integrated fuzzy multi-criteria decision-making approach under vague environment," Master of Science in Maritime Affairs, Malmö, Sweden, 2017.

[12] J. Ren and M. Lützen, "Fuzzy multi-criteria decision-making method for technology selection for emissions reduction from shipping under uncertainties," Transportation Research Part D: Transport and Environment, vol. 40, pp. 43-60, 2015/10/01/ 2015.

[13] K. Andersson, S. Brynolf, J. Lindgren, and M. Wilewska-Bien, Shipping and the Environment - Improving Environmental Performance in Marine Transportation. 2016.

[14] J. Ren and M. Lützen, "Selection of sustainable alternative energy source for shipping: Multi-criteria decision making under incomplete information," Renewable and Sustainable Energy Reviews, vol. 74, pp. 1003-1019, 2017/07/01/ 2017.

[15] S. Brynolf, F. Baldi, and H. Johnson, "Energy Efficiency and Fuel Changes to Reduce Environmental Impacts," in Shipping and the Environment - Improving Environmental Performance in Marine Transportation, K. Andersson, S. Brynolf, J. Lindgren, and M. Wilewska-Bien, Eds., 2016.

[16] A. I. Ölçer, M. Kitada, D. Dimitrios, and F. Ballini, Trends and Challenges in Maritime Energy Management. 2018.

[17] L. A. Zadeh, "The concept of a linguistic variable and its application to approximate reasoning-I," Information Sciences, vol. 8, no. 3, pp. 199-249, 1975/01/01/ 1975.

[18] J. Ren and H. Liang, "Measuring the sustainability of marine fuels: A fuzzy group multi-criteria decision making approach," Transportation Research Part D: Transport and Environment, vol. 54, pp. 12-29, 2017/07/01/ 2017.

[19] H. Wang and S. Nguyen, "Prioritizing mechanism of low carbon shipping measures using a combination of FQFD and FTOPSIS," Maritime Policy \& Management, vol. 44, no. 2, pp. 187-207, 2017/02/17 2017

[20] E. B. Beşikçi, T. Kececi, O. Arslan, and O. Turan, "An application of fuzzy-AHP to ship operational energy efficiency measures," Ocean Engineering, vol. 121, pp. 392-402, 2016/07/15/ 2016.

[21] B. Sahin and T. L. Yip, "Shipping technology selection for dynamic capability based on improved Gaussian fuzzy AHP model," Ocean Engineering, vol. 136, pp. 233-242, 2017/05/15/ 2017.

[22] J.-F. Helfre and P. A. C. Boot, "Emission Reduction in the Shipping Industry: Regulations, Exposure and Solutions," Sustainalytics, 2013.

[23] Ø. Rødseth, L. Perera, and B. Mo, "Big data in shipping Challenges and opportunities," in Proceedings of the 15th International Conference on Computer Applications and Information Technology in the Maritime Industries (COMPIT 2016), Lecce, Italy, 2016

[24] I. Zaman, K. Pazouki, R. Norman, S. Younessi, and S. Coleman, "Challenges and Opportunities of Big Data Analytics for Upcoming Regulations and Future Transformation of the Shipping Industry," Procedia Engineering, vol. 194, pp. 537-544, 2017/01/01/ 2017.

[25] DNVGL. IMO DCS (Data Collection System) [Online] Available: https://www.dnvgl.com/maritime/imo-des/index.html

[26] DNVGL. EU MRV Regulation [Online] Available: https://www.dnvgl.com/maritime/eu-mrv-regulation/index.html IBM. (2016). The Four V's of Big Data [Online]. Available: https://www.ibmbigdatahub.com/infographic/four-vs-big-data.

[28] L. P. Perera and B. Mo, "Ship performance and navigation information under high-dimensional digital models," Journal of Marine Science and Technology, 2019.

[29] A. E. Hassanien, A. T. Azar, V. Snasael, J. Kacprzyk, and J. H. Abawajy, "Big data in complex systems," in $S B D$, vol. 9: Springer, 2015.

[30] L. P. Leifsson, H. Sævarsdóttir, S. P. Sigurðsson, and A. Vésteinsson, "Grey-box modeling of an ocean vessel for operational optimization," Simulation Modelling Practice and Theory, vol. 16, no. 8, pp. 923-932, 2008/09/01/ 2008.

[31] X. Sun, X. Yan, B. Wu, and X. Song, "Analysis of the operational energy efficiency for inland river ships," Transportation Research Part D: Transport and Environment, vol. 22, pp. 34-39, 2013/07/01/ 2013.

[32] L. Mak, M. Sullivan, A. Kuczora, and J. Millan, "Ship performance monitoring and analysis to improve fuel efficiency," in 2014 Oceans - St. John's, 2014, pp. 1-10.

[33] K. Sasa et al., "Evaluation of ship performance in international maritime transportation using an onboard measurement system - in case of a bulk carrier in international voyages," Ocean Engineering, vol. 104, pp. 294-309, 2015/08/01/2015.

[34] D. G. Trodden, A. J. Murphy, K. Pazouki, and J. Sargeant, "Fuel usage data analysis for efficient shipping operations," Ocean Engineering, vol. 110, pp. 75-84, 2015/12/01/ 2015.

[35] B. P. Pedersen and J. Larsen, "Modeling of Ship Propulsion Performance," presented at the World Maritime Technology Conference WMTC2009, 2009. 
[36] E. Bal Beşikçi, O. Arslan, O. Turan, and A. I. Ölçer, "An artificial neural network based decision support system for energy efficient ship operations," Computers \& Operations Research, vol. 66, pp. 393-401, 2016/02/01/2016.

[37] D. Bocchetti, G. Group, I. A Lepore, B. Palumbo, and L. Vitiello, "A statistical control of the ship fuel consumption," presented at the International Conference on the Design \& Operation of Passenger Ship, London, UK, 2013.

[38] A. Coraddu, L. Oneto, F. Baldi, and D. Anguita, "Ship efficiency forecast based on sensors data collection: Improving numerical models through data analytics," in OCEANS 2015 - Genova, 2015, pp. 1-10.

[39] H. Lee, N. Aydin, Y. Choi, S. Lekhavat, and Z. Irani, "A decision support system for vessel speed decision in maritime logistics using weather archive big data," Computers \& Operations Research, vol. 98, pp. 330-342, 2018/10/01/2018.

[40] X. Yan, K. Wang, Y. Yuan, X. Jiang, and R. R. Negenborn, "Energy-efficient shipping: An application of big data analysis for optimizing engine speed of inland ships considering multiple environmental factors," Ocean Engineering, vol. 169, pp. 457-468, 2018/12/01/ 2018.

[41] L. P. Perera and B. Mo, "Marine Engine-Centered Data Analytics for Ship Performance Monitoring," Journal of Offshore Mechanics and Arctic Engineering, vol. 139, no. 2, pp. 021301-021301-8, 2017.

[42] L. P. Perera and B. Mo, "Data analysis on marine engine operating regions in relation to ship navigation," Ocean Engineering, vol. 128, pp. 163-172, 2016/12/01/2016.

[43] L. P. Perera and B. Mo, "Ship speed power performance under relative wind profiles in relation to sensor fault detection," Journal of Ocean Engineering and Science, vol. 3, no. 4, pp. 355-366, 2018/12/01/ 2018.

[44] L. P. Perera and B. Mo, "Machine Intelligence Based Data Handling Framework for Ship Energy Efficiency," IEEE Transactions on Vehicular Technology, vol. 66, no. 10, pp. 8659-8666, 2017. 